\title{
Autoantibodies and immunoglobulins in collagenous colitis
}

\author{
J Bohr, C Tysk, P Yang, D Danielsson, G Järnerot
}

\begin{abstract}
Background-The aetiology and pathogenesis of collagenous colitis are unknown. Autoimmunity has been suggested, but no serological findings have supported such a theory.

Aims and Methods-Serum from 38 collagenous colitis patients and 38 matched healthy controls was analysed for autoantibodies - that is, antinuclear antibodies, antineutrophil cytoplasmic antibodies, smooth muscle and mitochondrial antibodies, rheumatoid factor and antibodies to thyroglobulin and microsomal antigen, together with antibodies to endomysium, gliadin, and cardiolipin. The serum values of IgA, IgG, IgM, and IgG-subclasses, and complement factors $\mathrm{C} 3$ and $\mathrm{C} 4$ were also determined.

Results-In patients with collagenous colitis the mean value of IgM was significantly increased $2.5 \mathrm{~g} / \mathrm{l}(95 \% \mathrm{CI} ; 1.9,3.2)$ compared with $1.4 \mathrm{~g} / 1(95 \% \mathrm{CI} ; 1 \cdot 2,1 \cdot 7)$ in controls $(p=0.002)$. Antinuclear antibodies occurred in nine of 38 patients compared with three of 38 controls, this difference was not statistically significant $(p=0 \cdot 11)$. The results of all other immunoglobulins, complement factors, and specific antibodies showed no statistical difference between patients and controls. Conclusions-No firm evidence for an autoimmune genesis in collagenous colitis is found in this study, although the findings of a positive ANA-titre in some patients and an increased IgM level might give some support for this hypothesis. (Gut 1996; 39: 73-76)
\end{abstract}

Keywords: collagenous colitis, autoimmunity, autoantibodies, IgM, antinuclear antibodies (ANA), antineutrophil cytoplasmic antibodies (ANCA).

Department of Medicine, Division of Gastroenterology

J Bohr

C Tysk

$P$ Yang

G Järnerot

Department of Clinical Microbiology and

Immunology

D Danielsson

Örebro Medical

Centre Hospital,

Örebro, Sweden

Correspondence to: Dr J Bohr, Department of Medicine, Division of Gastroenterology, Örebro Medical Centre Hospital, S-701 85 Örebro, Sweden.

Accepted for publication 30 January 1996

Collagenous colitis (CC), first described by Lindström, ${ }^{1}$ is a bowel disease with chronic watery diarrhoea as the main symptom. It is characterised histopathologically by a subepithelial collagen layer adjacent to the basal membrane with a thickness of $10 \mu \mathrm{m}$ or more, infiltration of the lamina propria with inflammatory cells, epithelial lesions, and infiltration of the epithelium with lymphocytes. ${ }^{2}$

The aetiology and pathogenesis are unknown. An autoimmune genesis has been suggested, based on three findings; the association of CC with diseases of autoimmune origin reported in larger studies, ${ }^{34}$ the preponderance of elderly women in $\mathrm{CC}^{5}$ and the responsiveness to corticosteroids, ${ }^{67}$ all indicate that CC itself could be an autoimmune disease. Further support for this theory would be the finding of an autoantibody in CC patients and a high frequency of a HLA haplotype known to be associated with autoimmunity. ${ }^{8}$ HLA typing has been carried out in a study comparing patients with CC and lymphocytic colitis with healthy control persons, but no difference between patients with CC and control subjects was found. 9

In this study we investigated the frequency of autoantibodies, immunoglobulins, and complement factors in CC patients and healthy control persons, to test the hypothesis of autoimmunity.

\section{Methods}

PATIENTS

Serum samples from 38 patients with CC, all diagnosed according to both the clinical and histopathological criteria mentioned above, were obtained and stored at $-70^{\circ} \mathrm{C}$. The daily stool frequency at the time of serum sampling was registered in 34 of the patients (two failed to report and two had a split ileostomy). All medical treatment was registered. Any associated diseases of inflammatory origin were noted.

\section{CONTROL SUBJECTS}

Each patient had one control subject, matched for sex and age within two years. This group included healthy subjects without gastrointestinal symptoms, autoimmune or connective tissue disease, and were found among patients admitted for glaucoma operation $(n=15)$, blood donors $(n=21)$, and members of the staff at the department of medicine $(n=2)$.

\section{SEROLOGICAL METHODS}

\section{Autoantibodies}

Table I shows the range of autoantibodies examined for in serum specimens of patients and control subjects. IgG antinuclear antibodies (ANA) were determined by indirect immunofluorescence using cryostat sectioned liver ${ }^{10}$ and HEp-2 cells ${ }^{11}$ with serum initially diluted $1: 10$ and 1:25, respectively. Positive sera were subjected to end point titration and tests for anti-DNA antibodies with the use of Crithidia luciliae antigen. ${ }^{12}$ Fluorescein isothiocyanate labelled sheep antihuman IgG, purchased from Dakopatts Co (Denmark), was used as secondary antibody at a dilution recommended by the manufacturer and 
TABLE I Frequency of autoantibodies in patients and control subjects(\%)

\begin{tabular}{|c|c|c|c|c|c|c|c|c|c|c|c|c|}
\hline & Subjects & $A N A$ & $H E p-2$ & $p A N C A$ & $\begin{array}{l}\text { Liver-Ab } \\
\text { smooth muscle }\end{array}$ & $\begin{array}{l}\text { Liver-Ab } \\
\text { mitochon }\end{array}$ & $\begin{array}{l}R A, \\
R-W\end{array}$ & $\begin{array}{l}\text { Gliadin- } A B \\
\operatorname{Ig} A+\operatorname{Ig} G\end{array}$ & $\begin{array}{l}\text { Endomysium- } \\
A b\end{array}$ & $\begin{array}{l}\text { Cardiolipin- } \\
\mathrm{Ab}\end{array}$ & $\begin{array}{l}\text { Thyreoidea- } \\
\text { Ab } \\
\text { thyreoglobulin }\end{array}$ & $\begin{array}{l}\text { Thyreoidea- } \\
\text { Ab } \\
\text { microsomal }\end{array}$ \\
\hline $\begin{array}{l}\text { Patients } \\
\text { Controls }\end{array}$ & $\begin{array}{l}38 \\
38\end{array}$ & $\begin{array}{l}9(24) \\
3(8)\end{array}$ & $\begin{array}{l}9(24) \\
5(13)\end{array}$ & $\begin{array}{l}4(11) \\
1(3)\end{array}$ & $\begin{array}{l}2(5) \\
0\end{array}$ & $\begin{array}{l}3(8) \\
2(5)\end{array}$ & $\begin{array}{l}2^{\star}(5) \\
0\end{array}$ & $\begin{array}{l}2(5) \\
4(11)\end{array}$ & $\begin{array}{l}1(3) \\
0\end{array}$ & $\begin{array}{l}0 \\
1\end{array}$ & $\begin{array}{l}3(8) \\
0\end{array}$ & $\begin{array}{l}3(8) \\
1(3)\end{array}$ \\
\hline
\end{tabular}

Anti-DNA antibodies were absent in both patients and controls. *borderline.

checked by chess board titration. Cytoplasmic and perinuclear antineutrophil cytoplasmic antibodies (c- and pANCA) were analysed using indirect immunofluorescence according to a previously described method. ${ }^{13}$ Indirect immunofluorescence was also used to demonstrate IgG smooth muscle antibodies and mitochondrial antibodies using cryostat sections of rat kidney. ${ }^{14} 15$ A serum titre of $\geqslant 1: 25$ was considered positive and these sera were subjected to end point titration. Serum rheumatoid factor was determined with the standard Waaler-Rose test using sheep erythrocytes sensitised with a subagglutinating dose of rabbit antisheep erythrocyte antibodies. The test was calibrated against a WHO standard control serum obtained from Hoechst A/G, Germany (Hoechst OSHD 04/05) with titres expressed in units. Serum with $>64$ units was regarded positive, serum with 64 units was regarded borderline. ${ }^{16}$ Autoantibodies to human thyroglobulin and human thyroid microsomal antigen were determined with Boyden's passive haemagglutination test using test and control cells, diluent, positive, and negative control sera purchased from Murex Diagnostics, Dartford, England. A serum titre of $\geqslant 1: 80$ for antibodies to thyroglobulin was regarded positive, and of $\geqslant 1: 200$ for antibodies to thyroid microsomal antigen.

\section{Antibodies to endomysium and gliadin}

IgA endomysium antibodies were determined with indirect immunofluorescence with the use of cryostat sections of monkey oesophagus as described ${ }^{17}$ with an initial serum dilution of $1: 2 \cdot 5$. The end point titre was determined in positive sera. IgA and IgG gliadin antibodies were determined using diffusion in gel enzyme linked immunosorbent assay as described. ${ }^{18} \mathrm{~A}$ zone diameter of $\geqslant 11 \mathrm{~mm}$ for IgA gliadin antibodies and $\geqslant 14 \mathrm{~mm}$ for IgG gliadin antibodies was regarded positive.

\section{Anticardiolipin antibodies}

A solid phase ELISA test was used. Cardiolipin was purchased from Sigma Immunochemicals (Louisville, USA) and used to coat the well of microtitre plates as described. ${ }^{19}$ Serum specimens were tested at twofold dilutions of 1:5-1:160 with positive and negative controls. Sheep antihuman IgG alkaline phosphatase conjugate was used to detect IgG anticardiolipin antibodies with paranitrophenyle phosphate disodium as substrate. With the use of international standards the reactivity was expressed in IgG phospholipid units as described. ${ }^{19}$.
Determination of serum immunoglobulin concentrations and complement factors $\mathrm{C} 3 / \mathrm{C} 4$ Total serum IgG, IgA, and IgM, and complement factors $\mathrm{C} 3$ and $\mathrm{C} 4$ were determined by radial immunodiffusion according to Mancini. Immunoplates with polyclonal antibodies were purchased from Behringwerke A/S, Germany, and the recommendations by the manufacturer were followed. The determination of IgG subclasses $1,2,3$, and 4 were made by radial immunodiffusion with the use of monoclonal antibodies from Seward Laboratories, UK. The manufacturer's recommendations were followed. All determinations were done twice with variations between the tests of less than $\pm 10 \%$.

\section{STATISTICAL METHODS AND ETHICS}

Values are presented as medium (range) or mean with $95 \%$ confidence intervals (CI). For comparison of patients and controls the Student $t$ test, the Mann-Whitney U test, and Fisher's exact test were applied. Regression analysis was used to study the correlation between values of IgM and clinical parameters. To avoid the risk of mass significance a $p$ value $<0.01$ was considered significant. The study was approved by the ethical committee of Örebro Medical Centre Hospital.

\section{Results}

PATIENTS

The median age at the time of investigation was 65 (19-87) years. Thirty two of 38 patients were female. The median duration of symptoms from onset to the time of investigation was six (1-28) years. At the time of investigation 19 patients were untreated, 17 had various medical treatments other than corticosteroids, and two had split ileostomy. Twenty four patients had three or less stools per day, 10 had more than three stools per day. Fifteen patients had associated diseases: five had rheumatoid arthritis, four had thyroid disease including one with atoxic goitre, and Raynaud's phenomenon, the six others had insulin dependent diabetes mellitus, ankylosing spondylitis, coeliac disease, ulcerative proctitis, psoriasis, and chronic gastritis type A respectively. Twenty three patients had never had a disease of inflammatory (other than CC) or autoimmune origin.

\section{SERUM ANALYSIS}

All data on serological findings can be seen in Tables I and II. The mean value of IgM was significantly increased in patients, $2.5 \mathrm{~g} / 1(95 \%$ CI; $1.9,3.2$ ) compared with controls, $1.4 \mathrm{~g} / 1$ 
TABLE II Immunoglobulins and complement factors in serum, mean values $g / l(95 \%$ confidence intervals)

\begin{tabular}{lllllllllll}
\hline & Subjects & $I g A$ & $I g M$ & $I g G$ & $I g G 1$ & $I g G 2$ & $I g G 3$ & $\operatorname{IgG4}$ & $C 3$ & $C 4$ \\
\hline Patients & 38 & $2 \cdot 94$ & $2 \cdot 53^{\star}$ & $11 \cdot 07$ & $7 \cdot 76$ & $3 \cdot 30$ & $0 \cdot 36$ & $0 \cdot 36$ & $1 \cdot 47$ \\
& & $(2 \cdot 3,3 \cdot 5)$ & $(1 \cdot 9,3 \cdot 2)$ & $(10 \cdot 2,11 \cdot 9)$ & $(7 \cdot 0,8 \cdot 5)$ & $(2 \cdot 7,3 \cdot 9)$ & $(0 \cdot 3,0 \cdot 4)$ & $(0 \cdot 3,0 \cdot 5)$ & $(1 \cdot 4,1 \cdot 6)$ & $(0 \cdot 2,0.3)$ \\
Controls & 38 & $2 \cdot 58$ & $1 \cdot 44$ & $11 \cdot 09$ & $7 \cdot 42$ & $3 \cdot 75$ & $0 \cdot 38$ & $0 \cdot 51$ & $1 \cdot 54$ & $0 \cdot 26$ \\
& & $(2 \cdot 3,2 \cdot 9)$ & $(1 \cdot 2,1 \cdot 7)$ & $(10 \cdot 3,11 \cdot 9)$ & $(6 \cdot 5,8 \cdot 4)$ & $(3 \cdot 3,4 \cdot 2)$ & $(0 \cdot 3,0 \cdot 4)$ & $(0 \cdot 4,0 \cdot 6)$ & $(1 \cdot 5,1 \cdot 6)$ & $(0 \cdot 2,0 \cdot 3)$
\end{tabular}

IgM values for patients with and without associated diseases and with and without treatment were $(2 \cdot 2,2 \cdot 7,2 \cdot 6$, and $2 \cdot 4) \mathrm{g} / \mathrm{l}$ respectively. ${ }^{\star} \mathrm{p}=0 \cdot 002$.

$(95 \% \mathrm{CI} ; 1 \cdot 2,1 \cdot 7)(\mathrm{p}=0.002)$ (see Figure). The mean difference between patients and controls was $1 \cdot 1(95 \% \mathrm{CI} ; 0.4,1 \cdot 8)$. The sensitivity of IgM was 0.39 , the specificity was $0 \cdot 89$, and the positive predictive value 0.79 at a cut off value of $2 \cdot 2 \mathrm{~g} / \mathrm{l}$. The value of $\operatorname{IgM}$ was not correlated to the duration of the disease, $(r=0.03)$, to the stool frequency, $(r=0.08)$, or age, $(r=0 \cdot 17)$. There was no difference in IgM between the treated, $2.6 \mathrm{~g} / \mathrm{l}(95 \% \mathrm{CI} ; 1 \cdot 6,3 \cdot 6)$ and the untreated group, $2.4 \mathrm{~g} / 1(95 \% \mathrm{CI} ; 1.5$, $3.3)$ or between the group with associated, $2 \cdot 2 \mathrm{~g} / \mathrm{l}(95 \% \mathrm{CI} ; 1 \cdot 7,2 \cdot 7)$ and the group without associated diseases, $2 \cdot 7 \mathrm{~g} / 1(95 \% \mathrm{CI} ; 1 \cdot 7$, $3 \cdot 7)$. In the two patients with ileostomy IgM was normal. There was no correlation between the concentration of $\operatorname{IgM}$ and the concentration of any of the other serum immunoglobulins or complement factors.

ANA was detected in nine of 38 patients compared with three of 38 controls $(p=0 \cdot 11)$. There was no significant difference in the frequency of ANA between patients with associated diseases and those without. Among the ANA positive patients the mean IgM concentration was higher, $3.3 \mathrm{~g} / 1$ than among ANA negative patients, $2 \cdot 3 \mathrm{~g} / \mathrm{l}(\mathrm{p}=0.025)$.

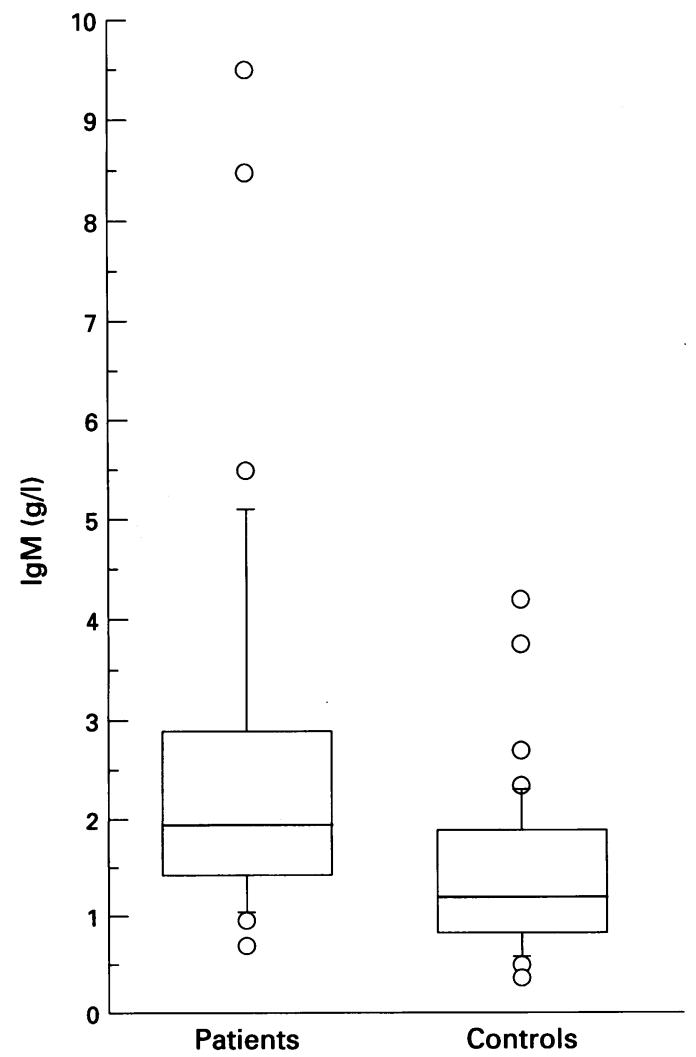

Box and whiskers plot showing the 10th, 25th, 75th, and 90th percentiles and median values of serum IgM for patients and control subjects.
There was no significant difference between patients and control subjects regarding the other investigated antibodies, immunoglobulins, and complement factors.

\section{Discussion}

Few studies have systematically investigated the presence of autoantibodies and immunoglobulins in CC. Perinuclear antineutrophil cytoplasmic antibodies (pANCA) have been found significantly increased in CC compared with controls though in a lower frequency than in ulcerative colitis. ${ }^{20}$ Antireticulin antibodies were found in one of 29 patients only. ${ }^{21}$ In three small series antinuclear antibodies (ANA) were studied. Four of eight patients were ANA positive in the first series, ${ }^{22}$ three of 13 in the second series, ${ }^{23}$ and one of 11 patients in the third series. ${ }^{24}$ These data are consistent with the present finding of ANA positivity in nine of 38 patients.

To the best of our knowledge, this is the first report of increased serum IgM in CC patients. In another small series of CC patients, immunoglobulins and complement $\mathrm{C} 3$ and $\mathrm{C} 4$ were studied. ${ }^{22}$ Normal values were reported in eight patients with the exception of low serum IgG in one patient. In addition, occasional findings of low IgA and IgG have been reported. ${ }^{325}$

An increased $\operatorname{IgM}$ is seen in the early phase of infections, constituting the primary antibody response. The findings that the onset of $\mathrm{CC}$ is described as subacute in some cases, ${ }^{26} 27$ and that antibiotic treatment has a temporary beneficial effect ${ }^{2728}$ show that CC might have an infectious aetiology. Our finding that faecal stream diversion in CC patients induced clinical and histopathological remission, ${ }^{29}$ supports this hypothesis. If so the increased IgM concentration would represent the primary antibody response. The lack of correlation, however, between $\operatorname{IgM}$ and duration of the disease, and the lack of increased IgG values contradicts this theory. An increase in serum IgM is seen also in primary biliary cirrhosis, an autoimmune disease of the liver that resembles CC regarding sex and age distribution and prevalence. ${ }^{30}$ Increased IgM is also seen during the clinical onset of type 1 diabetes mellitus, ${ }^{31}$ which is likewise suspected of having an autoimmune origin. However, as none of the specific autoantibodies commonly found in autoimmune disease were detected in this study, the support for an autoimmune genesis is not strong.

The threefold increased number of ANA positive patients compared with controls were not statistically significant. A non-significant 
difference of the mean IgM values in ANA positive and ANA negative patients was seen. Possibly, a subgroup of patients that is characterised by positive ANA and increased IgM may be identified. Whether this finding can be reproduced in a larger patient group remains to be shown. The clinical importance of IgM in CC deserves further investigation. Although the mean value was increased for the patient group, an overlap of individual values in patients and controls was seen. The sensitivity of $\operatorname{IgM}>2.2 \mathrm{~g} / \mathrm{l}$ (upper limit of the reference value in our laboratory) was 0.39 only, but the specificity was $0 \cdot 89$.

Consistent with other studies ${ }^{20}$ we found pANCAs in $11 \%$ of the patients. It was not significantly increased compared with the 38 matched controls. We have previously, in an abstract, reported results of pANCAs in ulcerative colitis, Crohn's disease, and CC compared with 190 unmatched controls. ${ }^{32}$ The different number of controls affects the statistical results, but obviously pANCAs have less significance in CC than in ulcerative colitis.

The age and sex distribution of the patients in this study are similar to other studies of CC. ${ }^{7}$ As the studied population represents most patients seen at our department with this disease, the risk of selection bias seems small. Both Student's $t$ test and the non-parametric Mann-Whitney U test were used for statistical analyses. Irrespective of method, similar results were achieved. We have chosen to present the results of Student's $t$ test as the samples are of considerable and equal size, and therefore the test is relatively robust with respect to violations of the distributional assumptions. Besides, confidence intervals were easily calculated from this method.

In summary, the mean value of $\operatorname{IgM}$ was significantly increased in CC, and ANA was present in nine of 38 patients compared with three of 38 controls, which gives some support for an autoimmune hypothesis. However, with respect to all other negative serological findings, the search for an autoantibody specific for CC is essential to prove the theory.

This study was financed by Örebro County Research Committee. Johan Bohr was financially supported by AB Committee. Johan Bohr was financially supported by AB
Pharmacia, Uppsala, Sweden, and Ping Yang by Orebro Pharmacia, Uppsala, Sweden, and Ping Yang by Orebro given by Associate Professor Lennart Bodin. This is all grategiven by Associate

1 Lindstöm CG. 'Collagenous colitis' with watery diarrhoea new entity? Pathologia Europaea 1976; 11: 87-9.

2 Bogomoletz WV. Collagenous, microscopic and lymphocytic colitis. An evolving concept. Virchows Archiv 1994 424: 573-9.

3 Jessurun J, Yardley JH, Giardiello FM, Hamilton SR, Bayless TH. Chronic colitis with thickening of the subepithelia collagen layer (collagenous colitis): histopathologic finding in 15 patients. Hum Pathol 1987; 18: 839-48.

4 Pierrugues R, Bories P, Barnéon G, Bernard N, Michel H. La colite collagène. Réflexions à propos de $\mathbf{4 0}$ malades. Gastroenterol Clin Biol 1989; 13: 811-5.

5 Bohr J, Tysk C, Eriksson S, Järnerot G. Collagenous colitis in Orebro, Sweden, an epidemiology study 1984-1993. Gut 1995; 37: 394-7.

6 Sloth H, Bisgaard C, Grove A. Collagenous colitis: a prospective trial of prednisolone in six patients. $\mathcal{F}$ Intern Med 1991; 229: 443-6.

7 Pimentel RR, Achkar E, Bedford R. Collagenous colitis. A treatable disease with an elusive diagnosis. Dig $\mathrm{Dis} \mathrm{Sci}$ 1995; 40: $1400-4$.

8 Snook J. Are the inflammatory bowel diseases autoimmune disorders? Gut 1990; 31: 961-3.

9 Giardiello FM, Lazenby AJ, Yardley JH, Bias WB, Johnson $\mathrm{J}$, Alianiello RG, et al. Increased HLA A1 and diminished HLA A3 in lymphocytic colitis compared to controls and patients with collagenous colitis. Dig Dis Sci 1992; 37: 496-9.

10 Fagraeus A, Bergquist NR. The raison d'etre of standards in indirect immunofluorescence. NY Acad Sci 1975; 254: 69-76.

11 Kozin F, Fowler M, Koeth SM. A comparison of the sensitivities and specificities of different substrates for the fluorescent antinuclear antibody test. Am f Clin Pathol 1980; 74: 785-90.

12 Aarden LA, deGroot ER, Faltkamp TEW. Immunology of DNA. III. Chritidiae luciliae, a simple substrate for the determinisation of anti-dsDNA with the immunofluoresdeterminisation of anti-dsDNA with the immunof

13 Yang $P$, Järnerot $G$, Danielsson D, Tysk C, Lindberg E. $P$-ANCA in monozygotic twins with inflammatory bowel disease. Gut 1995; 36: 887-90.

14 Anderson P, Small JN, Sobieszek A. Studies on the specificity of smooth muscle antibodies. Clin Exp Immunol 1976; 26: 57-66.

15 Klatskin G, Kantor FS. Mitochondrial antibody in primary biliary cirrhosis and other diseases. Ann Intern Med 1972; 77: 533-41.

16 Tarkovski A, Bjursten LM, Nilsson LÅ, Nygren H. False positive results in class-specific rheumatoid factor (RF) assays due to interaction between RF and Fc fragments of anti-immunoglobulin indicator reagents. $f$ Immunol Methods 1983; 58: 171-82.

17 Reunala EH, Chorzelski TP, Viander M, Sulej J, Vainio E, Kumar V, et al. IgA anti endomysial antibodies in dermatitis herpetiformis: correlation with jejunal morphology, gluten free diet and anti gliadin antibodies. $\mathrm{Br} \mathcal{J}$ Dermatol 1987; 117: 185-91.

18 Kilander AF, Dotevall G, Fällström FP, Gillberg RE, Nilsson LA, Tarkowski A. Evaluation of gliadin antibodies for detection of coeliac disease. Scand Gastroenterol 1983; 18: 377-83.

19 Harris EN (coordinator). Kingston anti-phospholipid antibody study (KAPS) group. The second international anticardiolipin standardization workshop. Am $\mathcal{f}$ Clin Pathol 1990; 94: 476-84.

20 Duerr RH, Targan SR, Landers CJ, Sutherland LR Shanahan F. Anti-neutrophil cytoplasmic antibodies in Shanahan F. Anti-neutrophil cytoplasmic antibodies in ulcerative colitis. Comparison with other colitide
rheal illnesses. Gastroenterology 1992; 100: 1590-6.

21 Greenson JK, Giardiello FM, Lazenby AJ, Peña SA, Bayless $\mathrm{TM}$, Yardley JH. Antireticulin antibodies in collagenous and lymphocytic (microscopic) colitis. Mod Pathol 1992, 3: $259-60$.

22 Sylwestrowicz T, Kelly JK, Hwang WS, Shaffer EA. Collagenous colitis and microscopic colitis: the watery
diarrhea-colitis syndrome. Am $\mathcal{f}$ Gastroenterol 1989: 84: 763-8.

23 Roubenoff R, Ratain J, Giardiello F, Hochberg M, Bias W, Lazenby A, et al. Collagenous colitis, enteropathic arthritis and autoimmune disease: results of a patient survey. $\mathcal{F}$ tis and autoimmune disease: result

24 Giardiello FM, Lazenby AJ, Bayless TM, Levine EJ, Bias WB, Ladenson PW, et al. Lymphocytic (microscopic) colitis. Clinicopathologic study of 18 patients and comparison to collagenous colitis. Dig Dis Sci 1989; 34: 1730-8.

25 Pariente EA, Chaumette M-T, Maitre F, Delchier J-C Soulé J-C, Bader JP. Colite collagène, déficit en IgA, maladie de Basedow et gastrite atrophique. Gastroentero Clin Biol 1985; 9: 738-41.

26 Grouls V, Vogel J, Sorger M. Collagenous colitis. Endoscopy 1982; 14: 31-3.

27 Pieterse AS, Hecker R, Rowland R. Collagenous colitis: a distinctive and potentially reversible disorder. $f$ Clin Pathol 1982; 35: 338-40.

28 Mogensen AM, Olsen JH, Gudmand-Højer E. Collagenous colitis. Acta Med Scand 1984; 216: 535-40.

29 Järnerot G, Tysk C, Bohr J, Eriksson S. Collagenous colitis and fecal stream diversion. Gastroenterology 1995; 109: 449-55.

30 Löfgren J, Järnerot G, Danielsson D, Hemdal I. Incidence and prevalence of primary biliary cirrhosis in a defined population in Sweden. Scand $\mathcal{F}$ Gastroenterol 1985; 20: 647-50.

31 Decraene T, Vandewalle C, Pipeleers D, Gorus FK Increased concentration of total IgM at clinical onset of type 1 (insulin-dependent) diabetes: correlation with IgM binding to cells. The Belgian Diabetes Registry. Clin Chem 1992; 38: 1762-7.

32 Yang P, Bohr J, Tysk C, Danielsson D, Järnerot G. Antineutrophil cytoplasmic antibodies in collagenous colitis and inflammatory bowel disease. Gut 1995; 37: A33. 